\title{
Microbiological Characteristics of "Mhom", a Thai Traditional Meat Sausage
}

\author{
W. Samappito ${ }^{1}$ B. Leenanon ${ }^{1}$ and Robert E. Levin ${ }^{* 2}$ \\ ${ }^{I}$ Department of Food Technology, Faculty of Technology, Khon Kaen University, 40002, Thailand \\ ${ }^{2}$ Department of Food Science, University of Massachusetts, Amherst, USA
}

\begin{abstract}
A Thai traditional meat sausage, namely Mhom, is a popular fermented meat product in the northeastern region of Thailand and yet little scientific information about Mhom is known. Seventy-one isolates of lactic acid bacteria were isolated from Mhom made in four provinces i.e. Chaiyaphum (CP), Khonkaen (KK), Maha Sarakham (MK), and Kalasin (KS). It was found that pHs of Mhom coded CP1, CP2, KK, MK and KS were 4.74, 4.94, 4.77, 4.30 and 4.76, respectively, and \% total acidity as lactic acid was $1.16,0.78,1.56,0.94$, and 0.86 , respectively. In addition, the total lactic acid bacteria in the products were $6.0 \times 10^{6}, 7.8 \times 10^{6}, 5.4 \times 10^{6}, 6.4 \times 10^{6}$ and $1.0 \times 10^{7} \mathrm{cfu} / \mathrm{g}$ for Mhom coded CP1, CP2, KK, MK and KS, respectively. The bacterial isolates were then subjected to biochemical tests using the API 50 CH and they were identified as Lactobacillus curvatus, L. delbrueckii, L. acidophilus, L. paracasei, L. brevis, L. pentosus, L. mesenteroides, L. plantarum, L. farciminis, Carnobacterium divergens, Pediococcus pentosaceus and Enterococcus. These strains of lactic acid bacteria found in Mhom may play significant roles in the ripening process resulting in unique sensory characteristics in the end products. They were naturally selected from the product microbiota by the ability to best compete under the prevailing conditions of the ecological niche. The lactic acid bacteria isolated and identified could be used as starters in Mhom production to obtain a more uniform sensory quality in the end products without undesirable flavors and microorganisms that may often be found in a natural fermentation in Mhom and the products could also be consumed safely.
\end{abstract}

Keywords: Mhom, fermented meat sausage, lactobacilli, Lactobacillus, Lactic acid bacteria.

\section{INTRODUCTION}

Lactic acid bacteria (LAB) and Micrococcaceae strains are important microorganisms used as starter cultures in meat fermentations. Their addition to meats may improve product safety and stability, provide diverse sensory characteristics and health benefits of probiotic characteristics as reported in a recent review by Lucke [1]. The most frequently isolated lactic acid bacteria from dry sausages processed with different technologies are Lactobacillus sakei, $L$. curvatus and $L$. plantarum $[2,3]$. The isolation and selection of lactic acid bacteria as starter cultures for meat fermentations present a considerable challenge to standardization and management of quality of dry fermented sausage.

With the different traditional formulations of dryfermented sausages, physico-chemical modifications occur including dehydration, fermentation of carbohydrates and acidification, development of a typical colour, lipolysis and oxidation of lipids, and proteolysis [4]. These changes are responsible for the organoleptic characteristics of the final products [4].

Mhom is a Thai traditional dry fermented sausage made from meats including pork or beef as a principal component along with internal organs i.e. liver or spleen and other ingredients such as salt, fried or cooked rice, garlic, and pepper. The raw material and ingredients are mixed, casing

*Address correspondence to this author at the Department of Food Science, University of Massachusetts, Amherst, MA 01003, USA; Tel: 413-5450187; Fax: 413-545-1262; E-mail: relevin@foodsci.umass.edu stuffed and tied. They are then kept at room temperature for about 2-3 days for fermentation. Mhom could be consumed raw or cooked. This fermented meat product has been widely developed and consumed in the northeastern region of Thailand. The fermentation is naturally mediated by indigenous bacteria resulting in rather non-uniform final products [5]. The bacteria found most commonly in Thai fermented meat products are lactobacilli, pediococci and micrococci. The precise roles of these bacteria on the quality of the products have not been fully understood [5]. Developments in meat fermentation have been focusing on application of defined starter cultures for a better control of fermentation and product consistency [6]. In addition to difficulties in obtaining product consistency, pathogens in raw fermented sausage still cause food safety problems.

The study of the ecology of fermented sausages is of primary importance to understand the physical and chemical changes during fermentation and maturation. The objectives of this study were to determine the different microbial groups in Thai traditional fermented meat sausage (Mhom) and identify the microorganisms involved.

\section{MATERIALS AND METHODS}

\section{Samples}

The experiment was carried out at the Department of Food Technology, Khon Kaen University, Khon Kaen, Thailand. Five Mhom samples were collected from the local markets in the Northeastern region of Thailand including Khon Kaen, Maha Sarakham, Chaiyaphum and Kalasin 
provinces. Mhom were produced according to the traditional method (without the use of starter cultures). The basic initial sausage mixture included beef meat, liver, salt, fried or cooked rice, pepper, sucrose, garlic, and spices. Samples were taken immediately after casing, 30 days after ripening and then transported to the laboratory under refrigeration (below $4{ }^{\circ} \mathrm{C}$ ).

\section{Microbiological Analysis}

Mhom samples were assayed for (1) aerobic plate counts (2) lactic acid bacteria (3) Micrococcaceae (4) coliforms (5) enterococci (6) Escherichia coli O157:H7 (7) Staphylococcus aureus, and (8) yeasts and molds. Ten grams of each sample were aseptically transferred to a sterile stomacher bag with $90 \mathrm{ml}$ of saline-peptone water $(\mathrm{NaCl}, 2 \%$; bacteriological peptone, $0.1 \%$ and Tween $80,1 \%$ ). The preparation was mixed for $3 \mathrm{~min}$ in a stomacher. Additional decimal dilutions were prepared, and the following analyses were carried out: (1) aerobic plate counts on Plate Count agar incubated for $48 \mathrm{~h}$ at $30{ }^{\circ} \mathrm{C}$ (2) lactic acid bacteria on MRS agar incubated for $48 \mathrm{~h}$ at $30{ }^{\circ} \mathrm{C}$ under restricted oxygen conditions (2 GasPak envelopes; BBL, Baltimore, Maryland, USA) in an anaerobic jar (3) Micrococcaceae on mannitol salt agar (MSA) incubated for $48 \mathrm{~h}$ at $30{ }^{\circ} \mathrm{C}(4)$ coliforms on MacConkey agar incubated for $24 \mathrm{~h}$ at $37^{\circ} \mathrm{C}(5)$ enterococci on Streptococcus faecalis (SF) agar incubated for $72 \mathrm{~h}$ at 42 ${ }^{\circ} \mathrm{C}$ (6) Escherichia coli $\mathrm{O} 157: \mathrm{H} 7$ on Sorbitol MacConkey Agar (SMAC) incubated for $24 \mathrm{~h}$ at $37{ }^{\circ} \mathrm{C}$ (7) Staphylococcus aureus on Baird-Parker medium with egg yolk tellurite emulsion incubated at $37^{\circ} \mathrm{C}$ for 24 to $48 \mathrm{~h}$ and (8) Yeast and Molds on Sabouraud agar incubated for 48 to $72 \mathrm{~h}$ at $30{ }^{\circ} \mathrm{C}$. After counting, means and standard deviations were calculated. Ten colonies from MRS plates for each sample were randomly selected, transferred to MRS and brain hearth infusion (BHI) broth, incubated overnight at appropriate temperatures and stored at $-80{ }^{\circ} \mathrm{C}$ in the same liquid media containing $30 \%$ glycerol for further study. All isolates were pre- liminarily characterized for cell morphology and Gram's reaction.

\section{Characterization and Identification of Microbial Isolates from Mhom Samples}

Pure culture colonies from MRS plates were tested for Gram's reaction. Gram-positive isolates were stored at $80^{\circ} \mathrm{C}$ in MRS broth with $30 \%$ glycerol (v/v) (Merck, Darmstadt, Germany). The isolates were activated by two consecutive transfers in broth before use and identified to species level according to the methodology and characteristics described by Curk et al. [7] The carbohydrate fermentation profiles of the isolates were investigated using API $50 \mathrm{CH}$ strips and API CHL medium according to manufacturer's instructions (API system, Bio-Merieux, France) [8].

\section{Chemical Analysis}

Total acidity as lactic acid and $\mathrm{pH}$ were determined using the methods of Franco et al. [9]. All chemical determinations were made in triplicate for each sample.

\section{Statistical Analysis}

All the data reported below were evaluated in triplicate, in each of the samples. The statistical analysis of the data was carried out by analysis of the variance (ANOVA) and the Duncan's new multiple range test to show measurements which can be considered statistically different. A significance level of $\alpha=0.05$ was used.

\section{RESULTS}

\section{Counts of the Different Microbial Groups and their Rela- tionships with Chemical Properties}

Table 1 shows the chemical properties and the counts of the different microbial groups of Mhom samples collected from Chaiyaphum (CP), Khon Kaen (KK), Maha Sarakham $(\mathrm{MK})$, and Kalasin (KS) provinces. In general, the $\mathrm{pH}$ values of ready-to-eat Mhom samples (20-30 days of fermenta-

Table 1. Chemical and Microbiological Analysis of Ripened Mhom Samples $(n=5)$

\begin{tabular}{|c|c|c|c|c|c|c|}
\hline \multirow{2}{*}{$\begin{array}{l}\text { Microorganism } \\
(\text { cfu/g) }\end{array}$} & \multicolumn{6}{|c|}{ Sources } \\
\hline & CP1 & CP2 & MK & KK & KS & Average \\
\hline $\mathrm{pH}$ & $4.74 b$ & $4.94 \mathrm{a}$ & $4.30 \mathrm{c}$ & $4.77 b$ & $4.76 b$ & 4.70 \\
\hline Total acidity (\%) & $1.16 b$ & $0.78 \mathrm{~d}$ & $0.94 \mathrm{c}$ & $1.56 \mathrm{a}$ & $0.86 \mathrm{~cd}$ & 1.06 \\
\hline Aerobic plate count & $6.0 \times 10^{7} \mathrm{~b}$ & $6.1 \times 10^{6} \mathrm{~d}$ & $1.4 \times 10^{8} \mathrm{a}$ & $2.0 \times 10^{7} \mathrm{c}$ & $3.2 \times 10^{7} \mathrm{c}$ & $5.0 \times 10^{7}$ \\
\hline Yeast and Mold & $7.3 \times 10^{6} \mathrm{e}$ & $3.9 \times 10^{7} \mathrm{~b}$ & $1.2 \times 10^{7} \mathrm{~d}$ & $2.6 \times 10^{7} \mathrm{c}$ & $1.6 \times 10^{8} \mathrm{a}$ & $4.9 \times 10^{7}$ \\
\hline Lactic Acid Bacteria & $6.0 \times 10^{6} \mathrm{~b}$ & $7.8 \times 10^{6} \mathrm{~b}$ & $5.4 \times 10^{6} \mathrm{~b}$ & $6.4 \times 10^{6} \mathrm{~b}$ & $1.0 \times 10^{7} \mathrm{a}$ & $7.1 \times 10^{6}$ \\
\hline Micrococcaceae & $2.7 \times 10^{4} \mathrm{~d}$ & $7.5 \times 10^{5} \mathrm{a}$ & $2.8 \times 10^{4} \mathrm{~d}$ & $3.7 \times 10^{4} \mathrm{c}$ & $3.9 \times 10^{5} \mathrm{~b}$ & $2.5 \times 10^{5}$ \\
\hline Enterococci & $4.6 \times 10^{4} \mathrm{~d}$ & $6.8 \times 10^{4} \mathrm{c}$ & $1.9 \times 10^{4} \mathrm{e}$ & $9.6 \times 10^{4} \mathrm{~b}$ & $5.5 \times 10^{5} \mathrm{a}$ & $1.6 \times 10^{5}$ \\
\hline Staphylococcus aureus & $3.3 \times 10^{3} \mathrm{~d}$ & $2.7 \times 10^{6} \mathrm{a}$ & $9.8 \times 10^{3} \mathrm{~d}$ & $6.3 \times 10^{4} \mathrm{c}$ & $8.5 \times 10^{4} \mathrm{~b}$ & $5.7 \times 10^{5}$ \\
\hline Coliforms & $2.4 \times 10^{2} \mathrm{~d}$ & $9.6 \times 10^{2} \mathrm{~b}$ & $2.2 \times 10^{2} \mathrm{~d}$ & $6.2 \times 10^{3} \mathrm{a}$ & $3.3 \times 10^{2} \mathrm{c}$ & $1.6 \times 10^{3}$ \\
\hline E. coli $0517: \mathrm{H} 7$ & ND & ND & ND & ND & ND & \\
\hline
\end{tabular}

LAB: Lactic acid bacteria, CP: Chaiyaphum, MK: Maha Sarakham, KK: Khon Kaen, KS: Kalasin.

Total acidity (\% acidity as lactic acid), ND: not detected.

Superscript letters with different letters in the same row, indicate significant difference $(p \leq 0.05)$ analyzed by Duncan's new multiple range tests. 
tion/ripening) were virtually similar, with the values in the range of 4.30 to 4.94 as the $\mathrm{pH}$ values of the samples coded CP1, CP2, KK, MK and KS were 4.74, 4.94, 4.77, 4.30 and 4.76 respectively, with the average value of 4.70 . The MK coded sample was found to have the lowest $\mathrm{pH}$ value (4.30). Moreover, the \% total acidities as lactic acid were 1.16, 0.78, 1.56, 0.94 and 0.86 for samples coded CP1, CP2, KK, MK and KS, respectively, with the average value of 1.06 . The highest acidity $(p \leq 0.05)$ was observed in the KK coded sample.

The results of the microbiological analyses of ripened Mhom are shown in Table 1. The Mhom samples showed high counts of all microbial groups indicating high microbial contamination in the raw materials used in their manufacture. Mhom from the five sources showed a total aerobic count in the range of $6.1 \times 10^{6}$ to $1.4 \times 10^{8} \mathrm{cfu} / \mathrm{g}$ and MK coded sample was found to have the highest aerobic plate count $\left(1.4 \times 10^{8} \mathrm{cfu} / \mathrm{g}\right)$ while $\mathrm{CP} 2$ coded sample was found to have the lowest count $\left(6.1 \times 10^{6} \mathrm{cfu} / \mathrm{g}\right)$. Also, the yeast and mold counts were found in the range of $7.3 \times 10^{6}$ to $1.6 \times 10^{8} \mathrm{cfu} / \mathrm{g}$ with the average of $4.9 \times 10^{7} \mathrm{cfu} / \mathrm{g}$. In addition, LAB counts were $6.0 \times 10^{6}, 7.8 \times 10^{6}, 5.4 \times 10^{6}$ and $6.4 \times 10^{6} \mathrm{cfu} / \mathrm{g}$ for samples coded CP1, CP2, MK and KK, respectively which were not significantly different. Furthermore, Micrococcaceae counts were found in the range of $2.70 \times 10^{4}$ to $7.50 \mathrm{x}$ $10^{5} \mathrm{cfu} / \mathrm{g}$ with the average of $2.50 \times 10^{5} \mathrm{cfu} / \mathrm{g}$. The enterococci counts of Mhom samples from different locations were statistically significant. The highest enterococci count was found in KS coded sample. The Staphylococcus aureus counts also varied in the range of $3.30 \times 10^{3}$ to $2.70 \times 10^{6}$ $\mathrm{cfu} / \mathrm{g}$. The numbers of $S$. aureus in $\mathrm{CP} 2$ coded sample was the highest whereas the one in CP1 coded sample was the lowest $(p \leq 0.05)$. Coliform counts were found lower than $10^{4}$ cfu/g in all samples. E. coli $\mathrm{O} 517: \mathrm{H} 7$ was not detected in all samples.

\section{Microbial Isolation and Identification}

Tables $\mathbf{2}$ and $\mathbf{3}$ show strain identities of the isolates from Mhom samples by using the BioMérieux (France) API-50 $\mathrm{CH}$ rapid test and distribution of those ones in Mhom samples among five different sources in Northeastern region of Thailand. The results revealed the identities of the 71 isolates, with isolates from MRS agar identified as 63 lactobacilli including Lactobacillus plantarum (44 isolates), Lactobacillus delbrueckii (4 isolates), Lactobacillus paracasei (4 isolates), Lactobacillus curvatus (3 isolates), Lactobacillus acidophilus (2 isolates), Lactobacillus brevis 1 (2 isolates), Lactobacillus brevis 3

(2 isolates), Lactobacillus pentosus (1 isolate), and Lactobacillus mesenteroides (1 isolate) with $88.73 \%$ of the extensively dominant isolates grown on MRS agar along with Pediococcus pentosaceus 1 (5 isolates), Pediococcus pentosaceus 2 (2 isolates) and Carnobacterium divergens (1 isolate). Obviously, Lactobacillus plantarum was the most frequently isolated species (61.97\%) from Mhom. Also, L. delbrueckii presented a similar proportion to that of $L$. paracasei. The distributions of the strains isolated from the 5 sources of Mhom samples are shown in Table $\mathbf{3}$.

L. plantarum was the most frequently isolated species (61.97\% of the total isolates) and have been shown to predominate in Mhom products. Similar percentages of strains isolated from Mhom were Pediococcus pentosaceus $1, L$. delbrueckii, L. paracasei and $L$. curvatus as 7.04, 5.63, 5.63 and $4.23 \%$, respectively. The largest number of isolates identified as LAB was found in CP1 $(43.66 \%$ of the total isolates), followed by $\mathrm{MK}, \mathrm{CP} 2, \mathrm{KK}$, and $\mathrm{KS}$, respectively.

\section{DISCUSSION}

Mhom, a Thai traditional sausage, is characterized by acidity with final $\mathrm{pH}$ of about 4.5 . The samples in this study were collected from 4 different locations in the Northeastern

Table 2. LAB Strains Isolated from Mhom

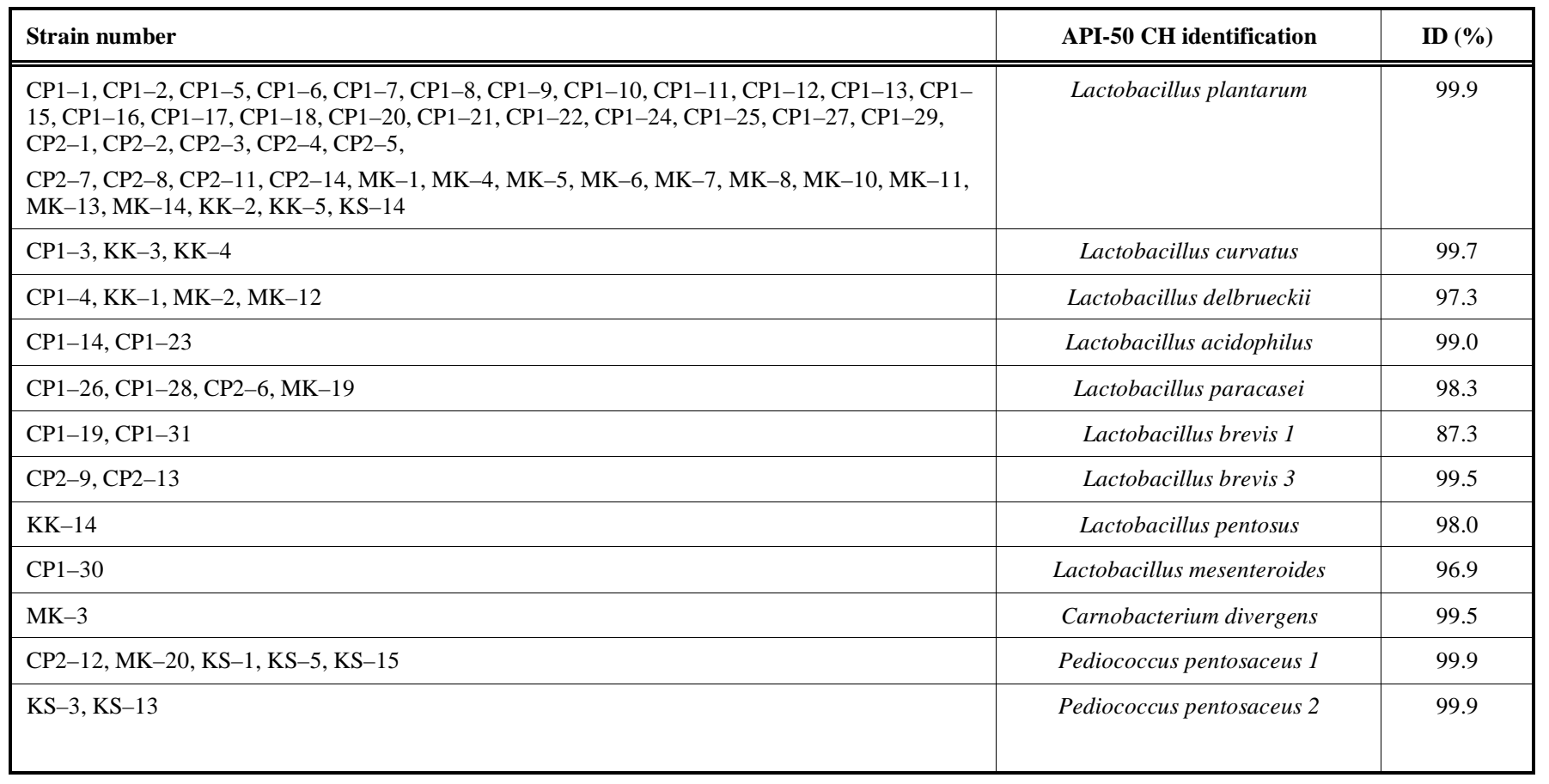


Table 3. Distribution of LABs in Mhom from Five Different Sources in Northeastern Region of Thailand. Identification Based on API 50 CH

\begin{tabular}{|c|c|c|c|c|c|c|c|}
\hline \multirow[t]{2}{*}{ Species } & \multicolumn{7}{|c|}{ Numbers of isolates identified } \\
\hline & CP1 & CP2 & MK & KK & KS & Total isolates & $(\%)$ \\
\hline Lactobacillus plantarum & 22 & 9 & 10 & 2 & 1 & 44 & 61.97 \\
\hline Lactobacillus curvatus & 1 & - & - & 2 & - & 3 & 4.23 \\
\hline Lactobacillus delbrueckii & 1 & - & 2 & 1 & - & 4 & 5.63 \\
\hline Lactobacillus acidophilus & 2 & - & - & - & - & 2 & 2.82 \\
\hline Lactobacillus paracasei & 2 & 1 & 1 & - & - & 4 & 5.63 \\
\hline Lactobacillus brevis 1 & 2 & - & - & - & - & 2 & 2.82 \\
\hline Lactobacillus brevis 3 & - & 2 & - & - & - & 2 & 2.82 \\
\hline Lactobacillus pentosus & - & - & - & 1 & - & 1 & 1.41 \\
\hline Lactobacillus Mesenteroides & 1 & - & - & - & - & 1 & 1.41 \\
\hline Carnobacterium divergens & - & - & 1 & - & - & 1 & 1.41 \\
\hline Pediococcus pentosaceus 1 & - & 1 & 1 & - & 3 & 5 & 7.04 \\
\hline Pediococcus pentosaceus 2 & - & - & - & - & 2 & 2 & 2.82 \\
\hline Total isolates & 31 & 13 & 15 & 6 & 6 & 71 & 100 \\
\hline$(\%)$ & 43.66 & 18.31 & 21.13 & 8.45 & 8.45 & 100 & \\
\hline
\end{tabular}

region of Thailand i.e., Chaiyaphum (CP), Khon Kaen (KK), Maha Sarakham (MK), and Kalasin (KS) provinces. The average $\mathrm{pH}$ value (4.7) of the Mhom after ripening was suitable for consumption which was lower than the $\mathrm{pH}$ values of some fermented meat products reported in the literature reviews $[3,10]$. However, the average $\mathrm{pH}$ value of the Mhom was similar to those obtained by other researchers in various sausages $[11,12]$. The low $\mathrm{pH}$ greatly extends its shelf life by inhibiting the growth of many food spoilage and pathogenic bacteria. Since it is normally uncooked, to ascertain the safety of sausages from survival and growth of some pathogenic microorganisms naturally contaminated in meat, it is recommended that sausages with $\mathrm{pH}$ lower than 4.6 are safe for consumption $[13,14]$. The low $\mathrm{pH}$ caused by the high acidifying capability of the indigenous lactic acid bacteria microflora results in the reduction of Micrococcaceae and Enterococci counts [15]. The Mhom samples in this study were from different areas in the northeast of Thailand and they were made differently depending on availability of ingredients and individual local tastes. Type and amount of ingredients could affect the microbial population in Mhom from different areas. In addition, starter cultures which were indigenous microorganisms in each area could be different. For the above two reasons, the fermentation in the five Mhom samples in this study possibly yielded different acids. Total acidity shown in Table $\mathbf{1}$ was expressed as lactic acid which is a major organic acid usually found in products fermented by lactic acid bacteria. In contrast, the final $\mathrm{pH}$ resulted from all acids present in the samples. Thus, acids other than lactic acid produced by heterofermentative lactic acid bacteria were also responsible for the low $\mathrm{pH}$ in Mhoms while they had little effect on the total acidity. For these reasons, total acidity in this study was not necessarily directly related to $\mathrm{pH}$. This indicates that $\mathrm{pH}$ measurement may not be a good quality indicator for home-made Mhom. However, for a product like yogurt which is fermented by homoferementative lactic acid bacteria [34], $\mathrm{pH}$ is used as a direct measure of acidity. In general, the total acidity increased significantly in the first seven days of ripening and, afterwards, more slowly until the 14th day of ripening, when it gradually decreased until the end of the ripening process. The decrease of the values of total acidity could be related to the development of microbial flora, fundamentally moulds and yeasts, capable of consuming lactic acid [11].

During the last few years novel benefits of adding specific LAB strains to our food are being discovered. LAB play an important role in the ripening of fermented meat, improve safety and stability of the sausages and provide health benefits by probiotic characteristics as reported in a recent review by Lucke [1]. In agreement with the results obtained by other authors in previous studies carried out on other meat sausages [16], the LAB were the major microbial groups. The average counts of LAB observed in our study was $7.10 \times 10^{6} \mathrm{cfu} / \mathrm{g}$. This average value was similar to those observed in androlla, a Spanish traditional pork sausage [17], Botillo, a Spanish traditional pork sausage [18] and Greek fermented sausage [19] and they are lightly higher than those observed in sausages produced in the North East of Italy [3], dry-cured bacon, a Spanish traditional meat product [20] and buffalo sausage [21].

Fermented sausages are considered good substrates for the growth of moulds and yeasts. Studies carried out with different yeast starters (mainly Debaryomyces hansenii, Candida famata) have shown the contribution of yeasts to the development of colour (by removing the oxygen) and 
flavour [22], due to their ability to degrade peroxides, lipolytic activity and, to a lesser degree, proteolytic activity. Furthermore, yeasts protect sausages from the adverse effects of light. The counts of moulds and yeasts were in the range of $7.30 \times 10^{6} \mathrm{cfu} / \mathrm{g}$ to $1.60 \times 10^{8} \mathrm{cfu} / \mathrm{g}$. This may indicate the differences in sanitation practices of different manufacturing houses. Mould and yeast counts found in this study were quite similar to those reported in sucuk, a Turkish dryfermented sausage [33]. However, average mould and yeast counts in Mhom were slightly higher than those reported in androlla, a Spanish traditional pork sausage [17] and sausages produced in the North East of Italy [3]. Mould and yeast contamination in fermented meat products is common due to the microbial contamination of raw materials used in their manufacture, poor handling of sausage during processing and storage. However, these moulds and yeasts are not all pathogenic. In addition, the yeast counts help to explain the lactic acid and $\mathrm{pH}$ level in fermented meats [22]. Yeasts are potent consumers of lactic acid in foods which lead to an increase in the $\mathrm{pH}[22,23]$. This was evident in CP2 and KS samples which had a higher $(p \leq 0.05)$ count yeasts and $\mathrm{pH}$ than other samples.

Sausages with a short ripening time have more lactobacilli right from the early stages of fermentation. In contrast, sausages with longer maturation times contain higher numbers of Micrococcaceae [3]. Micrococcaceae and LAB are the most important microorganisms used as starter cultures in the processing of dry-fermented sausages. Micrococcaceae participate in the preservation of meat products, avoiding rancidness and developing the typical red colour due to catalase and nitrate reductase [24]. Some Micrococcaceae strains are able to produce antimicrobial substances. In this study, the high numbers of Micrococcaceae were found with values in the range of $2.70 \times 10^{4}$ to $7.50 \times 10^{5} \mathrm{cfu} / \mathrm{g}$. This average value was lightly higher than those reported in sausages produced in the North East of Italy [3].

The enterococci also play an important role in the ripening of the sausages [25], probably through proteolysis, lipolysis, and citrate breakdown, hence contributing to their typical taste and flavour and enhance colour stability, prevent rancidity and release various aromatic substances [2]. Enterococci have the ability to produce bacteriocins, the socalled enterocins, which are small peptides with antimicrobial activity towards closely related gram-positive bacteria including spoilage or pathogenic bacteria, such as Listeria. Moreover, enterococci are used in some countries as probiotics [26]. In present study, high counts of enterococci $\left(>10^{4}\right.$ $\mathrm{cfu} / \mathrm{g}$ ) were found in Mhom, especially, samples from $\mathrm{KK}$ and CP2. The average enterococci counts were $1.60 \times 10^{5}$ $\mathrm{cfu} / \mathrm{g}$. This average value is slightly lower than those reported in Greek dry-fermented sausage [2], sausages produced in the North East of Italy [3] and androlla, a Spanish traditional pork sausage [17]. Enterococci may be used as starter cultures in some foods and are commercially available as probiotic cultures for preventing and treating intestinal disorders in animals and humans [27]. However, this genus may also be negatively associated with foods due to its possible implication as an indicator of faecal contamination [28].

Staphylococcus aureus is an important foodborne pathogen in fermented meat products [29]. Production methods play a very important role for $S$. aureus to grow in dry and semi-dry sausage. For example, fermentation temperature applied at $30-40{ }^{\circ} \mathrm{C}$ gives possible growth of $S$. aureus and its enterotoxin production [30]. The first hours and days of fermentation are particularly critical. Since fermented sausage is not stable from the point of view of $\mathrm{pH}$ and $\mathrm{A}_{\mathrm{w}}$, complex microbiological activity occurs in the initial stage of fermentation [30]. Different types of fermented sausages have been implicated in staphylococcal food poisoning outbreaks. In this study, the $S$. aureus counts varied with values in the range of $3.3 \times 10^{3}$ to $2.7 \times 10^{6} \mathrm{cfu} / \mathrm{g}$. The average value $\left(5.7 \times 10^{5} \mathrm{cfu} / \mathrm{g}\right)$, and the individual values of each sample were within the wide range of $S$. aureus counts reported in the literatures for different raw-cured sausages [3, 17]. S. aureus could have contaminated the raw materials during the processing. This indicates the low standard of hygiene in the handling of the process and in the manufacturing plants. It is recommended that this product should be consumed as a cooked food. However, the counts of coliforms were lower than $10^{3} \mathrm{cfu} / \mathrm{g}$ whereas $E$. coli $0517: \mathrm{H} 7$, an important foodborne pathogen, was not detected in the tested samples.

A total of 71 isolates were obtained from MRS agar and 63 isolates were identified with the API-50 CH as lactobacilli (44 were identified as Lactobacillus plantarum, 3 as Lactobacillus curvatus, 4 as Lactobacillus delbrueckii, 4 as Lactobacillus paracasei, 2 as Lactobacillus acidophilus, 2 as Lactobacillus brevis 1, 2 as Lactobacillus brevis 3, 1 as Lactobacillus pentosus and 1 as Lactobacillus mesenteroides) with $88.73 \%$ of the extensively dominant isolates derived from MRS agar.

Lactobacillus plantarum was the main $(61.97 \%)$ species of Lactobacillus in Mhom, especially in the sample from CP1 (50\%). L. plantarum, together with L. curvatus, are the two lactobacilli species most commonly isolated from meat and meat products, including sausages elaborated with different technologies [31]. L. plantarum has also been isolated in other raw-cured sausages [32], but in larger proportion observed in this study. L. delbrueckii count presented a similar proportion to that of L. paracasei, accounted for $5.63 \%$ of the isolates. The total number of LAB species was the most abundant in $\mathrm{CP} 1$, followed by $\mathrm{MK}, \mathrm{CP} 2, \mathrm{KK}$ and $\mathrm{KS}$, respectively.

\section{CONCLUSIONS}

Mhom samples were collected from four different locations in the Northeastern regions of Thailand i.e., Chaiyaphum (CP), Khon Kaen (KK), Kalasin (KS) and Maha Sarakham (MK) provinces in order to determine their microbiological and hygienic qualities. These meat products are manufactured with traditional technologies without pure starter cultures. Their manufacture depends on the skill and experience of the meat manufacturer rather than being a process that is fully based on scientific and technological means. Hence, the process depends on the growth of autochthonous microflora which influences the flavour, texture, nutritional qualities, safety, and other characteristics of this type of sausage. The results showed high total aerobic plate counts, yeasts and moulds, LAB, Micrococaceae and Enterobacteriaceae. The LAB (above all homofermentative lactobacilli) were the main microbial group. E. coli $\mathrm{O} 157: \mathrm{H} 7$ 
was not detected in the products. High counts of $S$. aureus were observed; this indicates low hygienic practices. It is recommended that this product be consumed as a cooked food.

Further studies are necessary such as determination of the antimicrobial activity of the strains and their technological properties in Mhom production, considering the possible interactions among starter strains in the meat mixture.

\section{ACKNOWLEDGEMENTS}

This work was funded by the Commission on Higher Education and Postharvest Technology Innovation Center: KKU, and Agricultural Machinery and Postharvest Technology Research Center, KKU. We would like to gratefully acknowledge the staff of the Food Microbiology Laboratory, Department of Food Technology, Faculty of Technology, Khon Kaen University, Thailand, for their collaboration and providing laboratory facilities.

\section{REFERENCES}

[1] Lucke FK. Utilization of microbes to process and preserve meat. Meat Sci 2000; 56: 105-15.

[2] Papamanoli E, Tzanetakis N, Litopoulou-Tzanetaki E, Kotzekidou P. Characterization of lactic acid bacteria isolated from a Greek dry-fermented sausage in respect of their technological and probiotic properties. Meat Sci 2003; 65: 859-67.

[3] Comi G, Urso R, Iacumin L, Rantsiou K, et al. Characterization of naturally fermented sausages produced in the North East of Italy. Meat Sci 2005; 69: 381-92.

[4] Ordonez JA, Hierro EM, Bruna JM, de la Hoz L. Changes in the components of dry-fermented sausages during ripening. Crit Rev Food Sci Nutr 1999; 34(9): 329-67.

[5] Thiravattanamontri P, Tanasupawat S, Noonpakdee W, Valyasevi R. Catalases of bacteria isolated from Thai fermented foods. Food Biotechnol 1998; 12: 221- 38 .

[6] Kastnera S, Perretenb V, Bleulera H, Hugenschmidta G, Lacroixa C, Meile L. Antibiotic susceptibility patterns and resistance genes of starter cultures and probiotic bacteria used in food. System Appl Microbiol 2006; 29: 145-55.

[7] Curk MC, Hubert JC, Bringel F. Lactobacillus paraplantarum sp. nov., a new species related to lactobacillus paraplantarum. Int $\mathbf{J}$ System Bacteriol 1996; 46: 595-8.

[8] Ammor S, Dufour E, Zagorec M, Chaillou S, Chevallier I. Characterization and selection of Lactobacillus sakei strains isolated from traditional dry sausage for their potential use as starter cultures. Food Microbiol 2005; 22: 529-38.

[9] Franco I, Prieto B, Cruz JM, Lopez M, Carballo J. Study of the biochemical changes during the processing of Androlla, a Spanish dry-cured pork sausage. Food Chem 2002; 78: 339-45.

[10] Fontana C, Cocconcelli PS, Vignolo G. Monitoring the bacterial population dynamics during fermentation of artisanal Argentinean sausages. Int J Food Microbiol 2005; 103(2): 131-42.

[11] Salgado A, Garcia Fontan MC, Franco I, Lopez M, Carballo J. Biochemical changes during the ripening of Chorizo de cebolla, a Spanish traditional sausage. Effect of the system of manufacture (homemade or industrial). Food Chem 2005; 92: 413-24.

[12] Visessanguan W, Benjakul S, Panya A, Kittikun C, Assavanig A. Influence of minced pork and rind ratios on physico-chemical and sensory quality of Nham - a Thai fermented pork sausage. Meat Sci 2005; 69: 355-62.

[13] Paukatong KV, Kunawasen S. The Hazard Analysis and Critical Control Points (HACCP) generic model for the production of Thai pork sausage (Nham). Berliner Und Munchener Tierarztliche Wochenschrift 2001; 114: 1-4.

[14] Valyasevi R, Rolle RS. An overview of small-scale food fermentation technologies in developing countries with special reference to Thailand: scope for their improvement. Int J Food Microbiol 2002; 75: 231- 39 .

[15] Raccah M. Some aspects of meat fermentation. Food Microbiol 1992; 9: 55-65.

[16] Gonzalez B, Diez V. The effect of nitrite and starter cultures on microbial quality of "chorizo", a Spanish dry cured sausage. Meat Sci 2002; 60: 295-8.

[17] Fontan MCG, Lorenzo JM, Parada A, Franco I, Carballo J. Microbiological characteristics of "androlla", a Spanish traditional pork sausage. Food Microbiol 2007; 24: 52-8.

[18] Maria C, Fontan G, Lorenzo JM, Martinez S, Franco I, Carballo J. Microbiological characteristics of Botillo, a Spanish traditional pork sausage. LWT 2007; 40: 1610-22.

[19] Drosinos EH, Mataragas M, Xiraphi N, Moschonas G, Gaitis F, Metaxopoulos J. Characterization of the microbial flora from a traditional Greek fermented sausage. Meat Sci 2005; 69: 307-17.

[20] Vilar I, Fontan MCG, Prieto B, Tornadijo ME, Carballo J. A survey on the microbiological changes during the manufacture of drycured lacon, a Spanish traditional meat product. J Appl Microbiol 2000; 89: 1018-1026.

[21] Sachindra NM, Sakhare PZ, Yashoda KP, Narasimha Rao D. Microbial profile of buffalo sausage during processing and storage. Food Control 2005; 16: 31-5.

[22] Juan-Pablo E, Lopez-Diaz TM, Garcia-Lopez ML, Otero A, Moreno B. Yeast populations on Spanish fermented sausages. Meat Sci 2000; 54: 203-8.

[23] Walker HW. Spoilage of food by yeasts. Food Technol 1977; 31(2): 57-61.

[24] Martin A, Colin B, Aranda E, Benito MJ, Cordoba MG. Characterization of Micrococcaceae isolated from Iberian dry-cured sausages. Meat Sci 2007; 75: 696-708.

[25] Hugas M, Garriga M, Aymerich MT. Functionality of enterococci in meat products. Int J Food Microbiol 2003; 88: 223-33.

[26] Franz CMAP, Stiles ME, Schleifer KH, Holzapfel WH. Enterococci in foods-a conundrum for food safety. Int J Food Microbiol 2003; 88: 105-22.

[27] Stiles ME, Holzapfel WH. Lactic acid bacteria of foods and their current taxonomy. Int J Food Microbiol 1997; 36: 1-29.

[28] Franz CM, Holzapfel WH, Stiles ME. Enterococci at the crossroads of food safety. Int J Food Microbiol 1999; 47: 1-24.

[29] Kang DH, Fung DYC. Stimulation of starter culture for further reduction of foodborne pathogens during salami fermentation. J Food Prot 2000; 63(11): 1492-5.

[30] Kaban G, Kaya M. Effect of starter culture on growth of Staphylococcus aureus in sucuk. Food Control 2006; 17: 797-801.

[31] Schillinger U, Lucke FK. Identification of lactobacilli from meat an meat products. Food Microbiol 1987; 4: 199-208.

[32] Coppola S, Mauriello G, Aponte M, Moschetti G, Villani F. Microbial succession during ripening of Naples-type salami, a southern Italian fermented sausage. Meat Sci 2000; 56: 321-9.

[33] Aksu MI, Kaya M. Effect of usage Urtica dioica L. on microbiological properties of sucuk, a Turkish dry-fermented sausage. Food Control 2004; 15: 591-5.

[34] Robinson RK. "Yoghurt, role of starter cultures", in encyclopedia of dairy science, edited by H. Roginski, J. Fuquay, P. Fox (Academic Press, United Kingdom), 2002, pp. 1059-63.

\section{(c) Samappito et al.; Licensee Bentham Open.}

This is an open access article licensed under the terms of the Creative Commons Attribution Non-Commercial License (http://creativecommons.org/licenses/by-nc/3.0/) which permits unrestricted, non-commercial use, distribution and reproduction in any medium, provided the work is properly cited. 